Vol. 10(7) pp. 105-111, July 2016

DOI: 10.5897/AJFS2016.1445

Article Number: A0A9F5A59202

ISSN 1996-0794

Copyright (C) 2016

Author(s) retain the copyright of this article

http://www.academicjournals.org/AJFS

\title{
Sensory evaluation of extruded quality protein maize- based supplementary foods
}

\author{
Elina Maseta $^{1,2 \star}$, Theobald C. E. Mosha ${ }^{1}$, Cornelio N. Nyaruhucha ${ }^{1}$, and Henry Laswai ${ }^{1}$ \\ ${ }^{1}$ Department of Food Technology, Nutrition and Consumer Sciences, College of Agriculture, Sokoine University of \\ Agriculture, P.O. Box 3006, Chuo Kikuu, Morogoro, Tanzania. \\ ${ }^{2}$ Department of Food and Nutrition, Open University of Tanzania, P. O. Box 23409, Dar es salaam, Tanzania.
}

Received 31 March, 2016; Accepted 20 May, 2016

\begin{abstract}
Maize porridge is widely consumed by children less than five years of age in Tanzania and other countries. The aim of this study was to evaluate the sensory attributes and the overall acceptability of the extruded quality protein maize-based supplementary foods for children in Tanzania. Two ready-touse supplementary foods were produced by extrusion cooking (quality protein maize-soybeanscommon beans and quality protein maize-soybeans-cowpeas) using the following food ingredients: quality protein maize, soybeans, common beans and cowpeas. Sugar, vitamins and mineral premix were added. These products were tested against a control diet made from common maize, soybeans, millet, wheat and groundnuts. A panel of sixty consumers was involved in the evaluation of sensory attributes of the porridge samples and overall acceptability was determined using 5 point Hedonic scale. Descriptive analysis was performed by 11 trained panelists using the lexicon developed. Statistical analysis was performed using analysis of variance and principal component analysis. Consumer evaluation revealed that quality protein maize-soybeans-common beans porridge was rated higher $(p<0.05)$ for aroma (4.6) and taste (4.6) than all porridge samples tested. Despite higher rating in aroma and taste, all the porridges (quality protein maize-soybeans-common beans, quality protein maize-soybeans-cowpeas and conventional porridge) were equally acceptable $(p>0.05)$ by the test panelists. Mean scores for overall acceptability of quality protein maize-soybeans-common beans, quality protein maize-soybeans-cowpeas and conventional porridge were 4.6, 4.3 and 4.2 , respectively. All the three porridges were differentiated $(p<0.05)$ using the identified language for quantitative descriptive study. The sensory attributes of colour, oiliness, aroma, sweetness, liking and aftertaste in principal component 1 distinguished experimental porridges from the control. However, all the food products could be described by viscosity, sweetness and colour in principal component 2 . This was an indication that test diets, quality protein maize-soybeans-common beans and quality protein maizesoybeans-cowpeas resembled the control diet by some attributes namely, aroma, aftertaste and sweetness and therefore, had higher potential for acceptance by consumers.
\end{abstract}

Key words: Supplementary food, sensory attributes, consumer preferences, principal component analysis, Tanzania.

\section{INTRODUCTION}

Child under-nutrition is often widespread where staple foods are mostly plant-based and consumption of animal- based foods is limited due to high prices that many people cannot afford. Throughout the developing world, 
$34 \%$ of the children under the age of five years are stunted, 25\% are underweight while $10 \%$ are wasted (Fanzo, 2012). In Tanzania, 42\% of children under the age of five years are stunted, $16 \%$ are underweight while $5 \%$ are wasted (NBS [Tanzania] and ICF Macro, 2011). These nutritional deficiencies have been linked to several causes, such as inappropriate feeding practices, high prevalence of infections and intake of foods that are low in nutrient quantity and quality. In Tanzania, the most common foods introduced to young children are made from maize, more often nothing is added to it to improve the protein and/or micronutrient contents. Intake of plain maize porridge has been associated with under-nutrition for children under the age of five years (Desalegn et al., 2015). Maize is low in amino acids lysine, tryptophan and micronutrients which are needed for optimal child growth and some of these are lost during processing of flour.

Various approaches have been devised in addressing the problem of under-nutrition globally. One of them was by International Maize and Wheat Improvement Center (CIMMYT) that involved developing maize cultivars (biofortification) with protein high in lysine and tryptophan called quality protein maize (QPM) (CIMMYT, 2003). QPM has chemical composition similar to the normal maize (CM) except that it contains higher levels of amino acids lysine and tryptophan (Boateng et al., 2012; Kiria et al., 2010). In spite of maize being predominantly consumed in Tanzania and that QPM has been adopted since 2001, there has been only few acceptability studies done on QPM. Some of these involved the use of QPM on making stiff porridge and snacks. However, there is limited information on the use of QPM in making supplementary foods for children. Therefore, this study focused on evaluating the sensory quality and acceptability of QPM-based supplementary foods for children.

\section{MATERIALS AND METHODS}

Quality protein maize (LISHE K-1) that was used for the study was purchased from Seliani Research Station, Arusha. Common maize (Zea mays), soybeans (Glycine max), common beans (Phaseolus vulgaris), cowpeas (Vigna unguiculata), vegetable oil and sugar were purchased from Morogoro Municipal central market. Micronutrient powder (MNP) used to fortify the diets was purchased from Tuboreshe Chakula Project, Dar es Salaam.

\section{Research design}

This was an experimental study in which a complete randomized design (CRD) was employed. The study was done at two levels, which were consumer liking/disliking and quantitative descriptive studies with the principal factor being the diet.
Table 1. Composition of the QPM-based supplementary food formulations and the control.

\begin{tabular}{lccc}
\hline \multirow{2}{*}{ Ingredients } & \multicolumn{3}{c}{ Formulation (g) } \\
\cline { 2 - 4 } & QSB & QSC & CP \\
\hline QPM & 52 & 54 & - \\
Soybean & 8 & 6 & 14 \\
Common maize & - & - & 57 \\
Cowpeas & - & 34 & - \\
Millet & - & - & 19 \\
Wheat & - & - & 5 \\
Common beans & 34 & - & - \\
Ground nut & - & - & 5 \\
Micronutrient powder & 1 & 1 & - \\
Sugar & 5 & 5 & - \\
Total & 100 & 100 & 100 \\
\hline QSB $=$ quality & protein & maize-soybean-common \\
beans: QSC $=$ quality & protein maize-soybean- \\
cowpeas: CP = Common maize-based flour.
\end{tabular}

\section{Product processing and formulation}

Separately, QPM, soybeans, common beans and cowpeas were cleaned by winnowing, removal of pebbles and chaff and washed in distilled water. QPM and soybeans were thereafter dehulled, cleaned and dried under the sun until a moisture content of $10 \%$ was attained. All ingredients were milled to fine flour (mesh size 0.4 $\mathrm{mm})$.

After extrusion, two products namely QPM-soybeans-common beans (QSB) and QPM-soybeans-cowpeas (QSC) were formulated as indicated in Table 1. The formulations were designed to meet the highest amino acid score and the desired amount of energy and fat according to the FAO/WHO/UNU (1985) Codex Alimentarius guidelines for supplementary foods for infants and young children. Lipid contents of the products were adjusted to $10 \%$ using vegetable oil. The control diet made from plain maize flour and commonly known as nutritious flour 'unga lishe' was purchased from Mansooma supermarket in Morogoro.

\section{Extrusion of foods}

Before extrusion, moisture content of the maize-legume blends was adjusted to $21 \%$. Extrusion of the composite flours was carried out in a commercial twin-screw extruder (Model JS $60 \mathrm{D}$, Qitong Chemical Industry Equipment Co. Ltd, Yantai, China). The following extrusion conditions were adopted: Temperatures 130 to $139^{\circ} \mathrm{C}$ (Zone 1) and 100 to $122^{\circ} \mathrm{C}$ (Zone 2) and a retention time of $2 \mathrm{~min}$. Main motor speed was set at $10.48 \mathrm{rpm}$ and feeder speed at 10.26 rpm. After extrusion, the extrudates were allowed to dry at room temperature overnight. Thereafter, the extrudates were milled and packaged in moisture proof polyethylene.

\section{Porridge preparation}

Two porridge samples were prepared from the extruded, fortified

\section{*Corresponding author. E-mail: emaseta@yahoo.co.uk. Tel: +255 713297846.}


flour of QSB and QSC. The third porridge sample , not extruded and unfortified 'the control' was made from conventional maize porridge. Porridge was made by first mixing $100 \mathrm{~g}$ of flour in $300 \mathrm{ml}$ of cold water to make slurry. The slurry was then gradually added, while stirring to $700 \mathrm{ml}$ of boiling water in a $2 \mathrm{~L}$ stainless steel saucepan. When the mixture boiled for $5 \mathrm{~min}$, the porridge was removed from the fire, cooled to approximately $60^{\circ} \mathrm{C}$ and kept in a thermos flask ready for testing. Since the flour for the control porridge was not extruded, it was kept to boil for $20 \mathrm{~min}$, and stirred every $5 \mathrm{~min}$.

\section{Consumer preference test}

A surrogate test panel of sixty mothers with average age of $24 \pm 8.2$ years was recruited for consumer acceptability test from a list of mothers attending the Reproductive and Child Health $(\mathrm{RCH})$ clinic at Magubike Health Centre, Kilosa District, Tanzania. Surrogate mothers who were also the biological mothers were involved in the study due to the fact that the target consumers who are children under the age of five years had no ability to objectively evaluate the sensory quality of the diet formulations. Prior to conducting the sensory tests, mothers were informed about the objectives of the study and requested to give their honest opinions after tasting the food products. Prior to testing, verbal consent was sought from each participant including declaring if they were allergic to any of the food components. Sensory attributes evaluated were colour, smell, texture (mouth feel) taste and overall acceptability using a modified 5-point Hedonic scale in which five and one represented the highest and the lowest orders of preference, respectively. Each panelist was provided with following, serviette, three samples of porridge and mineral water for rinsing the palate before and between testing the samples. During the test, $40-50 \mathrm{ml}$ of porridge was served in $200 \mathrm{ml}$ disposable white cups. After testing the sample, research assistants probed the mothers on the perception of the particular sample and filled the evaluation form.

\section{Training, lexicon development and product evaluation}

Product evaluation was carried out following the method described by Lawless \& Heymann (2010). Eleven panelists (9 females and 2 males), aged 22-24 years who were final year undergraduate students of the Sokoine University of Agriculture, Morogoro, Tanzania were used. Panelists were selected based on their availability, willingness to participate and knowledge of sensory evaluation. Furthermore, the panelists were screened if they had any of the following defects: taste and odour perception disorders and/or colour blindness. After screening, panelists who were willing to participate in the study signed a consent form to affirm their willingness to participate.

A 1-h training session involving tasting different porridge samples and other foodstuffs in order to generate descriptive terminologies that were used for the study was carried out for 7 days. The panelists individually examined the samples, generated descriptive terms and then discussed the results as a panel. List of nine agreed descriptors (whiteness, colour, sweetness, after taste, mouth feel, aroma, viscosity, liking and oiliness) on a 9 point unstructured line scales and their intensity terms were used in further training sessions (Table 2). Pre-testing was then carried out in order to identify any panelist who was not able to use the developed scale properly. In evaluating the samples, panelists were provided with an evaluation form, a bottle of mineral water, a pen, napkin and three cups of sample porridges for the actual testing.

\section{Ethical clearance}

Ethical clearance for this study was obtained from the National
Institute for Medical Research (NIMR). Informed consent was obtained from the participants before testing the products.

\section{Statistical analysis}

Statistical analyses were done using XLSTAT 2014.06 program. Overall acceptance of the porridge samples was tested by analysis of variance (ANOVA). When $p$-values were found significant $(p \leq 0.05)$, Turkey's HSD-test was performed to determine the individual differences among the three porridge samples. Correlation analysis was also carried out in order to determine the association between different quality attributes of the products. Principal component analysis (PCA) was performed to visualize how the sensory attributes differed across the products.

\section{RESULTS}

\section{Consumer evaluation of the porridge samples and preference}

Sixty eight percent of the mothers that participated in the study attained primary education while about one third $(32 \%)$ did not attain any formal education. The average age of the panelists was $28.4 \pm 8.5$ years. Panelists' rating of the porridges from the different flour formulations is presented in Table 3. It was noted that, extruded porridges required more flour ( $20 \%$ solids by weight) than common maize $(7 \%)$ in order to make porridge with the same consistency. High scores $(>3)$ were observed in this study for individual attributes and overall acceptability were "like moderately" to "like very much" for all the products. The sensory scores were generally high (4.2 to 4.9) for all attributes of the products, except for taste (3.6) that was observed in conventional porridge (CP). It was also observed that, panelists rated QSB significantly higher $(p<0.05)$ than the other porridge samples (QSC and $\mathrm{CP}$ ) in aroma and taste. Overall, none of the porridge samples was rejected by the panelists. This implied that, the developed products would be liked by consumers if marketed. The data indicated that, $\mathrm{CP}$ had slightly higher scores for texture (mouth feel) $(p>0.05)$ than the other porridge samples (QSB and QSC). This could partly be attributed to the dehulling, extrusion of the ingredients and subsequent re-grinding of the extrudates. Analysis of variance showed no significant difference $(p>0.05)$ in the acceptability of the porridge samples. Therefore, porridges from various flour formulations were equally liked by the panelists.

\section{Quantitative descriptive analysis}

Using the lexicon developed, descriptive sensory analysis showed that, extruded porridge samples had significantly $(p<0.05)$ more intense colour, mouth feel, whiteness, oiliness and liking, as compared to the conventional porridge (Table 4). Introduction of legumes (soy beans, cowpeas and common beans) and oil significantly 
Table 2. Definitions of sensory attributes used in descriptive analysis.

\begin{tabular}{|c|c|}
\hline Sensory attributes and their definitions & Reference \\
\hline \multicolumn{2}{|l|}{ Colour } \\
\hline \multicolumn{2}{|l|}{ Colour hue } \\
\hline Brown & $10 \%$ cocoa in water \\
\hline Red & Blood $=9$ \\
\hline \multicolumn{2}{|l|}{ Whiteness } \\
\hline Degree of white/black in the colour & Snow $=9$ \\
\hline \multicolumn{2}{|l|}{ Taste } \\
\hline \multicolumn{2}{|l|}{ Sweetness } \\
\hline Basic taste associated with sucrose & $10 \%$ sucrose in water $=9$ \\
\hline \multicolumn{2}{|l|}{ After Taste } \\
\hline Aftertaste stimulated by sucrose after 3 minutes & $10 \%$ sucrose $=9$ \\
\hline \multicolumn{2}{|l|}{ Oiliness } \\
\hline Taste related to cooking oil & Cooking oil=9 \\
\hline \multicolumn{2}{|l|}{ Texture } \\
\hline \multicolumn{2}{|l|}{ Texture } \\
\hline $\begin{array}{l}\text { Degree to which the sample feels smooth and free of lumps/particulates in } \\
\text { the mouth }\end{array}$ & Guava Azam juice ${ }^{\circledR}=9$ \\
\hline \multicolumn{2}{|l|}{ Aroma } \\
\hline \multicolumn{2}{|l|}{ Beany aroma } \\
\hline Aroma associated with raw bean & $\begin{array}{l}\text { Aroma of kidney beans boiled } \\
\text { for } 30 \text { minutes }=9\end{array}$ \\
\hline \multicolumn{2}{|l|}{ Viscosity } \\
\hline Viscosity & \\
\hline Resistance to flow & Shambani yoghurt ${ }^{\circledast}=9$ \\
\hline
\end{tabular}

Table 3. Mean sensory scores of QPM-based formulations by test panelists ${ }^{1,2}$.

\begin{tabular}{lccccc}
\hline \multirow{2}{*}{ Product } & \multicolumn{5}{c}{ Attributes } \\
\cline { 2 - 6 } & Aroma & Taste & Mouth feel & Colour & Acceptability \\
\hline QSB & $4.6 \pm 0.1^{\mathrm{a}}$ & $4.6 \pm 0.2^{\mathrm{a}}$ & $4.7 \pm 0.1^{\mathrm{b}}$ & $4.9 \pm 0.1^{\mathrm{a}}$ & $4.7 \pm 0.1^{\mathrm{a}}$ \\
QSC & $4.5 \pm 0.1^{\mathrm{ab}}$ & $4.2 \pm 0.2^{\mathrm{a}}$ & $4.7 \pm 0.1^{\mathrm{b}}$ & $4.7 \pm 0.1^{\mathrm{b}}$ & $4.3 \pm 0.1^{\mathrm{a}}$ \\
CP & $4.1 \pm 0.1^{\mathrm{b}}$ & $3.6 \pm 0.2^{\mathrm{b}}$ & $4.9 \pm 0.1^{\mathrm{a}}$ & $4.7 \pm 0.1^{\mathrm{b}}$ & $4.2 \pm 0.1^{\mathrm{a}}$ \\
P value & $.013^{\mathrm{a}}$ & .000 & $.310^{0}$ & .158 & .085 \\
\hline
\end{tabular}

${ }^{1} \mathrm{CP}$ : Common maize-based porridge, QSB: Quality protein maize-soybean-common bean, QSC: quality protein maize -soybean-cow peas. ${ }^{1,2}$ Mean values in a column with different superscripts are significantly different at $p<0.05$.

Table 4. Mean sensory attribute scores for three porridge samples ${ }^{1}$.

\begin{tabular}{lccccccccc}
\hline \multirow{2}{*}{ Product } & \multicolumn{7}{c}{ Attributes } \\
\cline { 2 - 10 } & Aroma & Aftertaste & Mouth feel & Colour & Liking & Sweetness & Viscosity & Oiliness & Whiteness \\
\hline CP & $5.36 \pm 1.9$ & $3.45 \pm 1.6$ & $7.55 \pm 1.1$ & $3.27 \pm 1.1$ & $4.36 \pm 1.9$ & $3.18 \pm 1.9$ & $8.73 \pm 0.9$ & $2.27 \pm 1.1$ & $5.91 \pm 2.0$ \\
QSB & $6.45 \pm 1.9$ & $3.55 \pm 2.3$ & $3.64 \pm 2.0$ & $6.55 \pm 1.0$ & $7.27 \pm 1.3$ & $4.18 \pm 1.5$ & $8.73 \pm 0.5$ & $4.18 \pm 2.2$ & $2.91 \pm 1.3$ \\
QSC & $5.64 \pm 2.2$ & $3.36 \pm 2.0$ & $2.91 \pm 1.8$ & $4.64 \pm 1.2$ & $7.18 \pm 1.1$ & $4.00 \pm 1.8$ & $6.73 \pm 1.0$ & $4.64 \pm 2.7$ & $5.18 \pm 1.5$ \\
P value & 0.422 & 0.977 & .000 & .000 & .000 & 0.371 & .000 & .031 & .000 \\
\hline
\end{tabular}

${ }^{1} \mathrm{CP}$ : Conventional porridge, QSB: quality protein maize-soybean-common bean, QSC: quality protein maize -soybean-cow peas. 
Table 5. Correlation matrix for the sensory attributes of the porridge samples ${ }^{1}$.

\begin{tabular}{|c|c|c|c|c|c|c|c|c|c|}
\hline & Whiteness & Colour & Sweetness & Aftertaste & Mouth feel & Aroma & Viscosity & Liking & Oiliness \\
\hline Whiteness & 1 & & & & & & & & \\
\hline Colour & -0.55 & 1 & & & & & & & \\
\hline Sweetness & -0.48 & 0.265 & 1 & & & & & & \\
\hline Aftertaste & -0.089 & 0.016 & -0.149 & 1 & & & & & \\
\hline Mouth feel & 0.256 & -0.422 & -0.144 & 0.191 & 1 & & & & \\
\hline Aroma & -0.155 & 0.017 & -0.191 & 0.418 & 0.097 & 1 & & & \\
\hline Viscosity & -0.14 & 0.163 & 0.149 & -0.183 & 0.32 & -0.159 & 1 & & \\
\hline Liking & -0.372 & 0.566 & 0.206 & 0.296 & -0.468 & 0.384 & -0.196 & 1 & \\
\hline Oiliness & -0.299 & 0.284 & -0.056 & 0.334 & -0.063 & 0.365 & -0.519 & 0.404 & 1 \\
\hline
\end{tabular}

${ }^{1}$ Numbers in bold represent significant correlations $(p \leq 0.05)$.

A

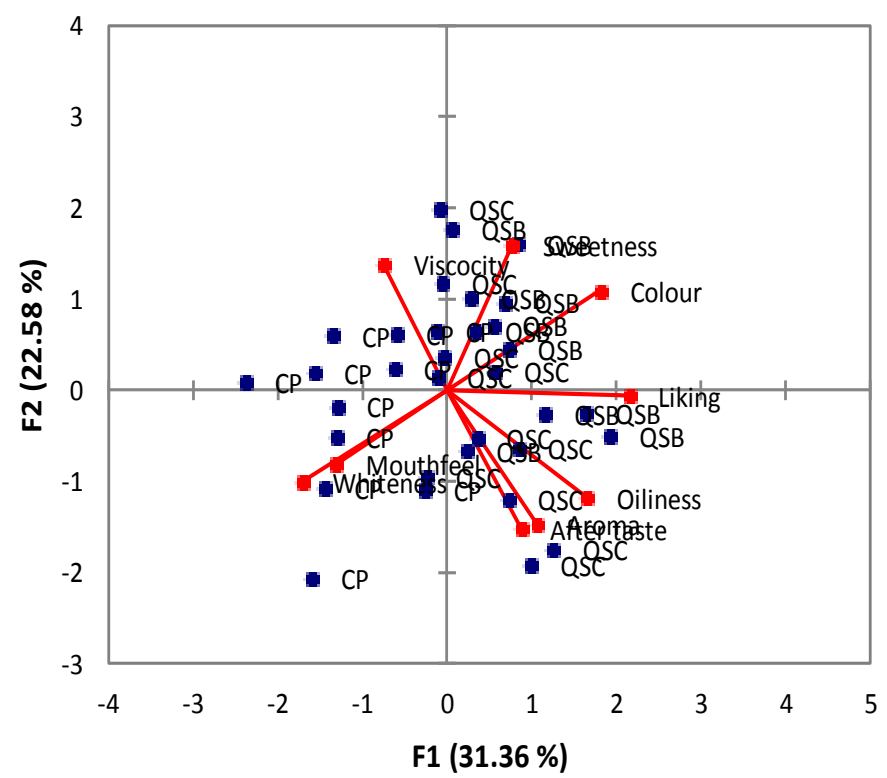

Biplot (axes F2 and F3: $37.14 \%$ )

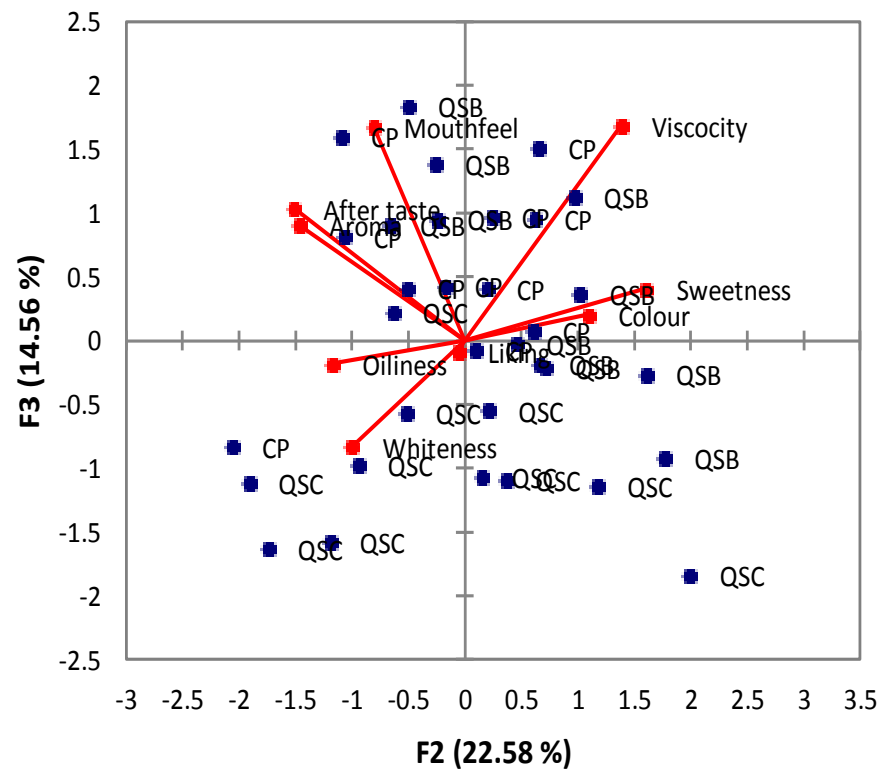

Figure 1. Principal component biplot of descriptive analysis of the three porridge samples; (a) Component factors 1 and 2; (b) Component factors 1 and 3 .

$(p<0.05)$ increased creamy flavor, oiliness and mouth feel in the extruded porridges. Porridge sample QSB was significantly more red than the rest. Extruded porridges (QSB and QSC) were less viscous than the CP.

Correlation analysis (Table 5) revealed that, the attributes tested (aroma, taste, mouth feel and colour) were the major determinants of acceptability for the developed products $(p<0.000)$. Taste attribute explained more than $60 \%$ of the variation, while the other attributes accounted for less than $50 \%$ of the variation. Only few of the tested attributes had significant association. Colour intensity could be associated with $60 \%$ of the liking by the panelists. Samples that had higher colour intensity were more likely to score higher liking by the panelists.

\section{Principal component analysis}

A two dimensional score plot of principal component analysis (PCA) (PC 1 and 2) indicated that, $54 \%$ of the variability was explained on the first two components (Figure 1a). Principal component 1 explained $31.4 \%$ of the variability and was characterized by aroma, aftertaste, oiliness, liking, colour and sweetness. These attributes are traditionally considered desirable in porridge. Colour was perfectly negatively correlated with whiteness. This suggested that, increase in colour intensity decreased whiteness. PCA further separated the porridge according to the processing methods. Extruded porridge samples (QSB and QSC) were more loaded in 
PC1. Principal component 2 explained $22.6 \%$ of the variability and was characterized by viscosity, sweetness and colour. In addition, viscosity was strongly but negatively correlated with aftertaste and aroma. This implied that, as porridge became thick and viscous the aftertaste and aroma intensities decreased.

The findings for PCA 2 and 3 explained $37 \%$ of the variability (Figure $1 \mathrm{~b}$ ). PC2 explained $22.6 \%$ of the variability and was characterized by colour, sweetness and viscosity. Furthermore, sweetness was negatively related to mouth feel and whiteness, implying that, as sweetness intensity increased, the decreased. PC 3 was characterised by aroma, aftertaste, mouth feel, viscosity, sweetness and colour.

The attribute of loadings for the first two principal components (Figure 1a) showed the relationship between various sensory attributes of the porridge samples. While QSC and QSB were highly loaded on the F1 and F2 components, respectively, CP was highly loaded in both F2 and F3 components (Figure $1 \mathrm{a}$ and b). This suggested that, test porridges QSB and QSC were best described by similar sensory attributes (colour, oiliness, aroma, sweetness, liking and aftertaste in the F1 component). All food samples, however, could be described by viscosity, sweetness and colour attributes (in the F2 component) and aroma, aftertaste, mouth feel, viscosity, sweetness and colour intensity attributes (in the F3 component).

ANOVA showed significant variation among the sensory attributes of the porridge samples except for sweetness, aftertaste and aroma (Table 4). CP had higher mouthfeel intensity than QSB and QSC. Sample QSC was less viscous as compared to the other porridge samples. This could be due to the fact that, it had the highest content of protein to starch ratio among the porridge samples. Turkey's post-hoc test indicated that, whiteness intensity was lower $(p<0.05)$ in QSB than the other porridge samples. Mouth feel intensity was significantly higher $(p<0.05)$ in CP than the other porridge samples. Likewise, CP was significantly more viscous $(p<0.05)$ than QSC and QSB. Porridge sample CP had significantly low oiliness intensity $(p<0.05)$ than the other porridge samples.

\section{DISCUSSION}

\section{Consumer evaluation study}

Results from consumer preference study showed that consumer acceptability of the porridge was much dependent on the sensory attributes of porridges namely aroma, taste, mouth feel and colour. Despite the fact that QSB was most preferred in terms of taste and aroma, all porridge samples were equally accepted. The observation that taste and aroma were best predictors of porridge acceptability in the current study, corroborated the findings of Amegovu et al. (2014). The findings that extruded products were more liked by consumers contrasted studies by Muoki et al. (2012) and Ndibalema (2011) who observed that, extruded products were less liked by consumers partly due to the development of volatile flavour compounds during extrusion which were not accustomed to the consumers.

Despite the fact that the test products used about 0.4:0.6 legume: cereal ratio, it did not affect the flavor by introducing beany flavour on the finished products. This could partly be due to extrusion cooking which has been reported to destroy the antinutritional factors and inactivate the lipoxygenase enzymes in legumes which are responsible for the beany flavour development (Singh et al., 2007). Extrusion cooking therefore could produce more nutrient rich foods from plants, a cheap alternative for substituting animal protein. Low viscosity of porridge samples QSB and QSC could be attributed to physical destruction of the starch granules during extrusion associated with mechanical shear and high temperatures during the process. Consequently, there was formation of amorphous water soluble carbohydrates and short chain polymers with low water binding capacities. High protein content in the extruded formulation could have contributed to the low viscosity of the QSB and QSC composites. Blending maize with legumes helped to increase the protein content while decreasing the carbohydrate levels in composite flours (Olapade and Aworh, 2012). This in turn helped to reduce viscosity. Low starch content and low viscosity in maize-legume blends has been reported elsewhere (Amagloh et al., 2012). Due to low viscosity of the formulations, less water was used during porridge preparation than was needed for the control (CP). Therefore, there was low energy and other nutrients density in the $\mathrm{CP}$ relative to the other formulations.

\section{Quantitative descriptive study}

In this study, panelists demonstrated that, colour intensity was related to liking intensity of the porridge samples. Samples that had higher colour intensity were more likely to score higher liking intensity by judges and vice versa. This finding is in agreement with Mahony (2011) and Nti and Lartey (2007) who observed that, colour intensity was related to liking intensity in peanut paste. The relationship between colour and liking intensity observed in the sensory study was reflected in the consumer evaluation study whereby panelists liked reddish colour of the porridge sample QSB which was caused by red pigmented bean variety used in its formulation. A study by Berhanu et al. (2014) involving the use of red coloured haricot bean in food formulation revealed a change in colour of the finished product that was also associated with increase in customer appeal for the product.

\section{Conclusion}

Sensory study revealed that, QSB was ranked highest in 
aroma and taste. Other attributes namely mouth feel, colour and acceptability were similar for QSB, QSC and $\mathrm{CP}$. Despite differences in aroma and taste, there was no significant difference in the overall acceptability of the products. This indicated that, all the products were equally preferred by the panelists. Descriptive analysis and consumer testing demonstrated distinctive sensory profiles for QSB, QSC and CP. Regarding consumer acceptability, intensities of oiliness, colour, viscosity, aroma and aftertaste of porridge samples were desirable attributes while viscosity, mouth feel and whiteness were undesirable attributes. It was concluded from this study that, food industry should maintain desirable sensory characteristics and minimize undesirable attributes when formulating products for children. The test products, QSB and QSC showed a great potential for being adopted as supplementary foods for infants and young children.

\section{Conflict of Interests}

The authors have not declared any conflict of interests.

\section{ACKNOWLEDGEMENTS}

The authors wish to thank The World Bank /The Open University of Tanzania, for financial support. They also acknowledge with thanks, the mothers and Sokoine University of Agriculture students for accepting to participate in the study.

\section{REFERENCES}

Amagloh FK, Mutukumira AN, Brough L, Weber JL, Hardacre A, Coad J (2012). Complementary food blends and malnutrition among infants in Ghana: A review and a proposed solution. Sci. Res. Essays 7(9):972-988.

Amegovu AK, Ogwok P, Ochola S, Yiga P, Musalima JH, Mandha J (2014). Sensory Acceptability of Sorghum Peanut Blend (SPB ) and Corn Soy Blend Plus ( CSB +) By Young Children With Moderate Acute Malnutrition in Karamoja, Uganda. J. Food Res. 3(2):17-26.

Berhanu G, Mesfin A, Kebebu A, Whiting SJ, Henry CJ (2014). Household food processing methods to enhance iron and zinc bioavailability in formulated haricot bean and maize complementary food. Afr. J. Food Sci. 8:190-195.
Boateng M, Okai D, Salifu AR, Ewool M (2012). A Comparative Study of two Normal Maize and two Quality Protein Maize Varieties - Effects on Growth Performance and Carcass Characteristics of Albino Rats. J. Anim. Sci. Adv. 2(9):787-792.

CIMMYT (2003). CIMMYT's Work for maize Systems and Farmers in sub-Saharan Africa. Mexico, DF (Mexico): CIMMYT. Mexico, DF (Mexico).

Desalegn BB, Abegaz K, Kinfe E (2015). Effect of Blending Ratio and Processing Technique on Physicochemical Composition, Functional Properties and Sensory Acceptability of Quality Protein Maize (QPM) Based Complementary Food. Int. J. Food Sci. Nutr. Eng. 5(3):121129.

Fanzo J(2012). The Nutrition Challenge in Sub-Saharan Africa. Working paper. United Nations Development Programme, Regional bureau for Africa.

FAO/WHO/UNU (1985). Energy and Protein Requirements. Report of a Joint FAO/WHO/UNU Expert Consultation. WHO Technical Report Series No. 724. WHO, Geneva. 207.

Kiria CG, Hester V, De Groote H (2010). Sensory Evaluation and Consumers' Willingness to Pay for Quality Protein Maize (QPM) using Experimental Auctions in Rural Tanzania. Contributed Paper presented at the Joint 3rd African Association of Agricultural Economists (AAAE) and 48th Agricultural Economists Association of South Africa (AEASA) Conference, Cape Town, South Africa, September 19-23, 2010. pp. 113-139.

Lawless H, Heymann H (2010). Sensory Evaluation of Food: Principles and Practices. Principles and Practices. (Heldman D. R., Ed.) (Second Ed.). Springer New York Dordrecht Heidelberg London.

Mahony AMY (2011). Effect of color on the odor, flavor, and acceptance properties of foods and beverages. Submitted in partial fulfillment of the requirements for the degree Master of Science. Kansas State University.

Muoki PN, de Kock HL, Emmambux MN (2012). Effect of soy flour addition and heat-processing method on nutritional quality and consumer acceptability of cassava complementary porridges. J. Sci. Food Agric. 92(8):1771-1779.

NBS [Tanzania] and ICF Macro (2011). Tanzania Demographic and Health Survey 2010. Dar-es-Salaam: NBS and ICF Macro.

Ndibalema D (2011). Effect of extrusion processing on the nutritional value and tannin content of sorghum - soybean composite supplementary products. A dissertation submitted in partial fulfillment of the requirements for the degree of Master of Science in food science of Sokoine University of agriculture. Morogoro, Tanzania.

Nti CA, Lartey A (2007). Effect of caregiver feeding behaviours on child nutritional status in rural Ghana. Int. J. Consum. Stud. 31(3):303309.

Olapade AA, Aworh OC (2012). Evaluation of extruded snacks from blends of acha (Digitaria exilis) and cowpea (Vigna unguiculata) flours: Int. J. Food Nutr. Sci. 14(3):210-217.

Singh S, Gamlath S, Wakeling L (2007). Nutritional aspects of food extrusion: A review. Int. J. Food Sci. Technol. 42(8):916-929. 